\title{
Detailed morphological description of Habronema clarki Foster \& Chitwood, 1937, a nematode parasite of capybaras Hydrochoerus hydrochaeris (Linnaeus, 1766) in Brazil
}

\author{
Descrição morfológica detalhada de Habronema clarki Foster \& Chitwood, 1937, \\ um nematódeo parasita de capivaras Hydrochoerus hydrochaeris (Linnaeus, 1766) no Brasil \\ Estevam Guilherme Lux Hoppe ${ }^{1 *}$; José Hairton Tebaldi ${ }^{1}$; Daniel Fontana Ferreira Cardia ${ }^{2}$ \\ ${ }^{1}$ Departamento de Medicina Veterinária Preventiva e Reprodução Animal, Faculdade de Ciências Agrárias e Veterinárias, \\ Universidade Estadual Paulista - UNESP, Jaboticabal, SP, Brasil \\ ${ }^{2}$ Programa de Pós-graduação em Medicina Veterinária - Preventiva, Departamento de Medicina Veterinária Preventiva e Reprodução \\ Animal, Faculdade de Ciências Agrárias e Veterinárias, Universidade Estadual Paulista - UNESP, Jaboticabal, SP, Brasil
}

Received September 24, 2013

Accepted March 13, 2014

\begin{abstract}
The genus Habronema has four valid species, of which only two are properly known. The present study aimed to describe in detail the morphology of Habronema clarki through optical and scanning electron microscopy analyses. Our results showed that the labial morphology of this parasite is closer to H. muscae than to H. microstoma. Even so, the characteristic pseudolabia and the slightly convex border of the dorsal and ventral lips are sufficient to distinguish these nematodes. Additional morphological data are presented, thus contributing to the knowledge on this little known nematode. In addition, this study provides new locality records for this species.

Keywords: Nematoda, optical microscopy, scanning electron microscopy, labial morphology.

\section{Resumo}

O gênero Habronema tem quatro espécies válidas, das quais apenas duas são propriamente conhecidas. O presente estudo visa descrever em detalhes a morfologia de Habronema clarki por meio de microscopia eletrônica de varredura e de luz. Os resultados demonstram que a morfologia labial do parasita é mais próxima de $H$. muscae que de H. microstoma. Ainda assim, os pseudolábios característicos e a borda discretamente convexa dos lábios dorsal e ventral são suficientes para se diferenciar esses nematódeos. Dados morfológicos adicionais são apresentados, contribuindo para o conhecimento deste nematódeo pouco conhecido. Em adição, este estudo representa um novo registro de localidade para a espécie.
\end{abstract}

Palavras-chave: Nematoda, microscopia óptica, microscopia eletrônica de varredura, morfologia labial.

\section{Introduction}

The Habronematoidea Chitwood \& Wehr, 1932, are a highly diverse group of nematode parasites of birds and mammals. Contrary to the International Code of Zoological Nomenclature, the taxon used as the basis for the superfamily is not the oldest, but the most recognized species: Habronema muscae (Carter, 1861) Diesing, 1861 (CHABAUD, 2009). Oddly, although there are four valid species in the genus Habronema Diesing, 1861, which is the type genus of this group, only $H$. muscae and Habronema microstoma (Schneider, 1866) Ramson, 1911 have been properly studied

\footnotetext{
*Corresponding author: Estevam Guilherme Lux Hoppe

Rod. Prof. Paulo Donato Castelane, s/n, CEP 14884-900,

Jaboticabal, SP, Brazil

e-mail: hoppe@fcav.unesp.br
}

regarding their biology (ANDERSON, 2000) and morphology (NAEM, 2007).

In Brazil, three species of this genus have been reported (VICENTE et al., 1997) and, of these, only Habronema clarki Foster \& Chitwood, 1937, seems to be native, since $H$. muscae and $H$. microstoma were probably introduced along with their natural host, the domestic horse.

Despite a recent record of this nematode in capybaras Hydrochoerus hydrochaeris (Linnaeus, 1766) in Bolivia (CASAS et al., 1995), the morphology of this nematode was only discussed in the original description, based on specimens obtained from Hydrochoerus isthmius Goldman, 1912, from Panama (FOSTER; CHITWOOD, 1937). There are no other records relating to the morphology of 
this nematode, and, particularly, its labial morphology, which is essential for the group (CHABAUD, 1958), is scarcely known.

The present study aimed to describe in detail the morphology of Habronema clarki, a nematode parasite of Hydrochoeridae rodents.

\section{Methodology}

\section{Specimens}

We analyzed 23 specimens deposited in the helminthological collection of the 'Prof. Dr. Orlando Ferrari' Animal Parasitic Diseases Laboratory, Department of Preventive Veterinary Medicine and Animal Reproduction, FCAV/UNESP, Jaboticabal, state of São Paulo, Brazil. These were obtained from a capybara in Bandeirantes, state of Paraná, Brazil. Specific identification of these nematodes was performed prior to this study, based on the original description of this species (FOSTER; CHITWOOD, 1937).

Three specimens were prepared for scanning electron microscopy analysis on the labial morphology and the others were processed using routine procedures for optical microscopy investigation.

\section{Scanning electron microscopy}

For scanning electron microscopy (SEM), the nematodes were post-fixed overnight with $2 \%$ osmium tetroxide at $23{ }^{\circ} \mathrm{C}$ for $12 \mathrm{~h}$. After that, the specimens were dehydrated in a graded acetone series, critical-point dried with liquid $\mathrm{CO}_{2}$, and then mounted on SEM stubs and coated with gold. This study was conducted using a JEOL JSM-5410 scanning electron microscope.

\section{Optical microscopy}

For optical microscopy, the parasites were clarified in $80 \%$ acetic acid (v/v) and beechwood creosote. Measurements in millimeters, expressed as the mean \pm standard deviation and range in parentheses, were obtained using an Olympus ${ }^{\circledR}$ BX-51 microscope equipped with QColor $3^{\oplus}$ image system. The images obtained were processed using the Image ProPlus ${ }^{\oplus}$ v.5.0 software. All measurements on morphological characteristics were based on data from ten specimens of each sex, unless otherwise stated.

\section{Results and discussion}

\section{Habronema clarki Foster \& Chitwood, 1937}

General. Large, whitish nematodes in vivo. The dorsal and ventral lips bear two papillae each, with the anterior border slightly convex. The pseudolabia are deeply trilobed, with amphids at their bases. The outer lobes are a little longer than the inner ones, and all three lobes are rounded at the distal extremity (Figure 1). Bilateral, symmetrical lateral alae may be observed along the body.

Females. Body is $21.276 \pm 1.608$ (18.853-23.529) in length and $0.336 \pm 0.018(0.296-0.361)$ in width. The stoma length is $0.090 \pm 0.008(0.074-0,100)$ and the esophagus length is $2.44 \pm 0.301(1.705-2.824)$. Nerve ring is situated at $0.269 \pm 0.020$ (0.241-0.293) from the anterior ending. The cervical papillae

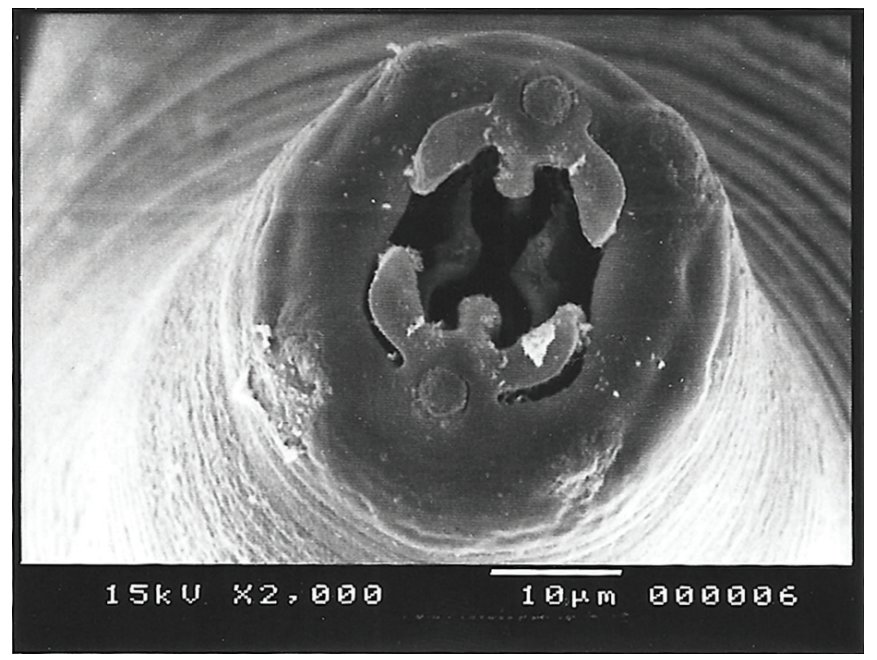

Figure 1. Habronema clarki. SEM of the anterior end of a male specimen. Note the trifurcate pseudolabia with a round amphid at their base and the simple dorsal and ventral lips. Labial papillae are eroded due to the relatively poor preservation of the specimens studied. Bar: $10 \mu \mathrm{m}$.

and excretory pore $(\mathrm{n}=7)$ are $0.205 \pm 0.017(0.181-0.232)$ and $0.339 \pm 0.020(0.302-0.367)$ from the anterior ending, respectively (Figure 2A. Cervical papillae not shown). The vulvar opening is ventral, $4.604 \pm 0.677(3.492-5.326)$ from the anterior portion. The tail is conical and the anus is $0.245 \pm 0.03(0.194-0.296)$ from the rounded tail tip (Figure $2 \mathrm{~B}$ ).

Males. Body is $12.372 \pm 1.012(10.530-14.560)$ in length and $0.236 \pm 0.029(0.198-0.277)$ in width. The stoma length is $0.082 \pm 0.011(0.055-0.095)$ and the esophagus length is $1.88 \pm 0.2354(1.426-2.147)$. The cervical papillae, nerve ring and excretory pore $(\mathrm{n}=6)$ are $0.185 \pm 0.023(0.146-0.213)$, $0.2294 \pm 0.018(0.190-0.249)$ and $0.276 \pm 0.027(0.252-0.328)$ distant from the anterior ending. The typical spirurid-type male tail has two caudal alae supported by four pairs of pre-cloacal pedunculated papillae and two pairs of asymmetrically arranged postcloacal pedunculated papillae. Ten small, sessile papillae can be seen at the tail tip. The right spicule is short, measuring $0.381 \pm 0.041$ (0.333-0.488) in length and the left one is long, twisted in the middle part and $0.752 \pm 0.038(0.695-0.807)$ in length. The gubernaculum is complex, longer than its width, measuring $0.060 \pm 0.005(0.053-0.069) \times 0.050 \pm 0.003(0.046-0.056)$.

\section{Taxonomic summary}

Type host. Hydrochoerus isthmius Goldman, 1912

Other host. Hydrochoerus hydrochaeris L., 1766

Site of infection. Mucosa of the stomach.

Type locality. Darien Province, Panama.

New locality record. Bandeirantes, state of Paraná, Brazil.

Collection information. Male and female vouchers were deposited in the Helminthological Collection of the Oswaldo Cruz Institute (CHIOC/Fiocruz), Rio de Janeiro, RJ, Brazil, under collection number CHIOC 35893, as wet mounts. Other 

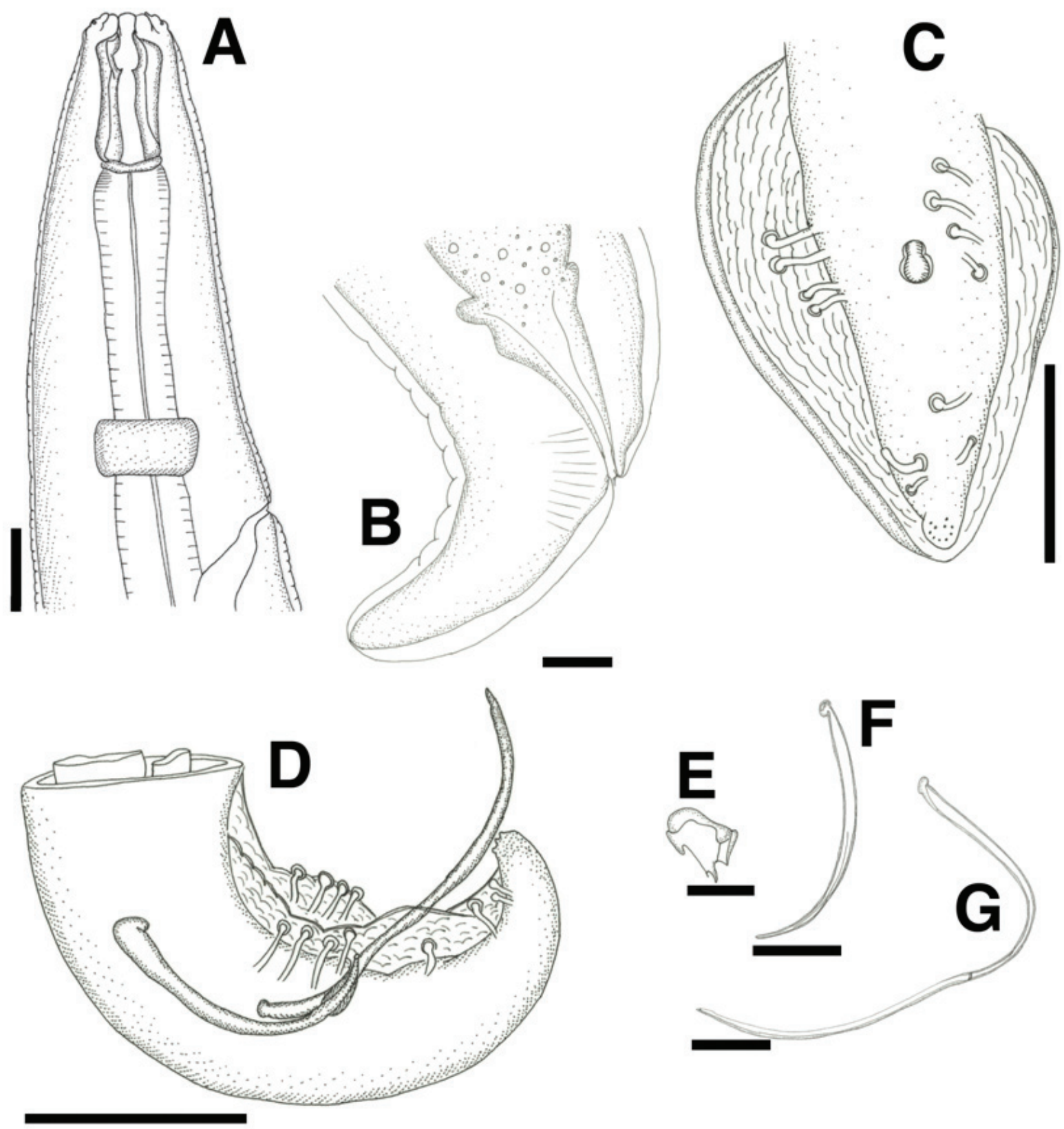

Figure 2. Habronema clarki. A. Female, anterior end, lateral view; B. Female, posterior end, lateral view; C. Male, tail, ventral view (spicules not drawn); D. Male, tail, lateral view; E. Gubernaculum, lateral view; F. Right spicule, left view; G. Left spicule, left view. Bars: 0.05 mm (Figures A, B, and E); $0.1 \mathrm{~mm}$ (Figures F and G); $0.25 \mathrm{~mm}$ (Figures C and D).

vouchers were deposited in the helminthological collection of the 'Prof. Dr. Orlando Ferrari' Animal Parasitic Diseases Laboratory, FCAV/UNESP, Jaboticabal, SP, Brazil, also as wet mounts.

\section{Discussion}

Among the Habronema species, only H. muscae shows a morphological pattern similar to $H$. clarki, with well-developed trifurcated pseudolabia, while $H$. microstoma has simple trapezoid pseudolabia (NAEM, 2007). The characteristic pseudolabia and the slightly convex border of the dorsal and ventral lips are sufficient to differentiate $H$. clarki from $H$. muscae. The description of the labial morphology was based on the SEM findings. Nonetheless, analysis of en face preparations is sufficient to view the pseudolabia and papillae. Remarkably, the labial morphology of Habronema zebrae Theiler, 1923, the fourth species of the Habronema genus, is still unknown. Further studies are important in order to evaluate the classification of the latter species within this genus.

In comparison with the other Habronema species registered in Brazil, $H$. clarki shows a longer stoma, but the general structure of the caudal portion of the male is identical to $H$. muscae and 
H. microstoma. However, the left spicule length, which is slightly less than the size proposed in keys for the Habronema species (Chabaud, 1958) and also in the original description (FOSTER; CHITWOOD, 1937), may be used for specific identification.

In the original description, Foster and Chitwood (1937) used the vaginal musculature as characteristic in the specific key that they provided. Moreover, the key proposed by Chabaud (1958) focused specific identification only on male characteristics. In our study, it was found that observation of the vaginal musculature may be very difficult in mature females because of their thickened body. We suggest that the stoma should be used as the identification criterion for females, especially in situations of monosexual infections.

Although this study represents the first official record of $H$. clarki in Brazil, previous studies have reported occurrences of Habronema nematodes in Brazilian capybaras in the states of São Paulo and Mato Grosso do Sul (SINKOC et al., 2004; TRAVASSOS, 1945), thus suggesting that this species has widespread distribution.

\section{Conclusion}

Based on the present data, the trifurcated pseudolabia could be an important characteristic of this genus and, therefore, should be studied in detail. Also, these characteristics should be included in future taxonomic keys in an attempt to improve the beta-taxonomy of this group. Additionally, new locality data is given in our study.

\section{References}

Anderson RC. Nematodes parasites of vertebrates: Their development and transmission. 2nd ed. Wallingford: CAB International; 2000. http:// dx.doi.org/10.1079/9780851994215.0000

Casas MC, Zalles LM, Patrick MJ, Dailey M. Intestinal helminths of capybara (Hydrochaeris hydrochaeris) from Bolivia. J Helminthol Soc Wash 1995; 62(1): 87-88.

Chabaud AG. Essai de classification des nématodes Habronematinae. Ann Par Hum Comp 1958; 33(4): 445-508.

Chabaud AG. Chapter 13. Spirurida. Spiruroidea, Habronematoidea and Acuarioidea. In: Anderson RC, Chabaud AG, Wilmott S, editors. Keys to the nematode parasites of vertebrates. Archival Volume. Wallingford: CAB International; 2009. p. 361-390.

Foster AO, Chitwood BG. A new nematode, Habronema clarki n. sp. (Spiruridae), from Hydrochoerus isthmius Goldman. Proc Helminthol Soc Wash 1937; 4(2): 64-65.

Naem S. The comparative morphology of three equine habronematid nematodes: SEM observations. Parasitol Res 2007; 101(5): 1303-1310. PMid:17610080. http://dx.doi.org/10.1007/s00436-007-0637-1

Sinkoc AL, Brum FA, Müller G, Brum JGW. Helmintos parasitos de capivara (Hydrochoerus hydrochaeris L. 1766) na região de Araçatuba, São Paulo, Brasil. Arq Inst Biol 2004; 71(3):329-333.

Travassos L. Relatório da excursão do Instituto Oswaldo Cruz ao Rio Paraná (Porto Cabral), em março e abril de 1944. Mem Inst Osw Cruz 1945; 42(1): 151-165. http://dx.doi.org/10.1590/S007402761945000100010

Vicente JJ, Rodrigues HO, Gomes DC, Pinto RM. Nematóides do Brasil. Parte V: Nematóides de mamíferos. Rev Bras Zool 1997; 14(S1): 1-452. 